Pacific Journal of Mathematics

MAXIMINIMAX, MINIMAX, AND ANTIMINIMAX THEOREMS 


\section{MAXIMINIMAX, MINIMAX, AND ANTIMINIMAX THEOREMS AND A RESULT OF R. C. JAMES}

\section{S. SIMONS}

This paper contains a number of minimax theorems in various topological and non-topological situations. Probably the most interesting is the following: if $X$ is a nonempty bounded convex subset of a real Hausdorff locally convex space $E$ with dual $E^{\prime}$ and each $\varphi \in E^{\prime}$ attains its supremum on $X$ then

$$
\left.\begin{array}{c}
\text { for all nonempty convex equicontinuous } Y \subset E^{\prime} \\
\inf _{y \in Y} \sup \langle X, y\rangle \leqq \sup _{x \in X} \inf \langle x, Y\rangle
\end{array}\right\} \text { (*). }
$$

It is also proved that if $\left(^{*}\right)$ is true and $X$ is complete then $X$ is $w\left(E, E^{\prime}\right)$-compact. Combining these results, a proof of a well known result of $R$. C. James is obtained.

We suppose throughout that $X \neq \phi, Y \neq \phi$, and $f: X \times Y \rightarrow R$. We write $\mathscr{F}(X)$ for $\{F: \phi \neq F \subset X, F$ is finite $\}$ and define $\mathscr{F}(Y)$ similarly. The maximinimax inequality is the relation

$$
\inf _{G \in \mathcal{F}(Y)} \sup _{x \in \mathcal{X}} \inf f(x, G) \leqq \sup _{F \in \mathcal{T}(X)} \inf _{y \in Y} \sup f(F, y)
$$

and the minimax inequality is the relation

$$
\inf _{y \in Y} \sup f(X, y) \leqq \sup _{x \in X} \inf f(x, Y) \text {. }
$$

The main result of this paper is Theorem 5, which gives some conditions under which (1) holds. These conditions are completely non-topological and depend only on the fact that certain functions attain their suprema on $X$. We prove Theorem 5 by defining a "remoteness" relation on the subsets of $Y$, but we point out that Theorem 5 can also be proved by first reducing the problem to the "iterated limits unequal" situation (by using the technique of Remark 8 and then the diagonal process) and then going through the same steps as in [6], Lemmas 1-7. The approach adopted here embodies a new type of diagonal argument (Lemmas 2 and 3) which might find applications elsewhere, and an argument similar to but subtler than that used in [9], Lemma 2. There is another proof of Theorem 5 that is "frontended" in the sense that we can choose the functions $k_{1}, k_{2}, \cdots$ of Theorem 5 by a purely inductive process without having first to choose a sequence $\left\{y_{n}\right\}_{n \geqq 1}$. The price one pays for the "frontendedness" is that the induction is more complicated and that is why we have avoided the alternative approach. 
Remarks 6, 7, and 8 give certain topological conditions under which (1) holds; the result in Remark 8 uses Theorem 5 and is considerably deeper than the other two.

In Lemma 11 we give some conditions (far from the best, but adequate for our purposes) under which (2) follows from (1) and thus derive some minimax Theorems in Theorem 12, Remark 13 and Theorem 14.

Theorem 15 is a converse minimax theorem and leads immediately to Theorem 16, which contains the result of James referred to in the title. Those sections of this paper that are needed for Theorem 16 are entitled "Lemma" and "Theorem", while those not so needed are entitled "Remark".

1. A maximinimax theorem with no topology and hardly any convexity.

Notation 1 . If $Z \neq \dot{\phi}$ we write $S_{Z}$ for "supremum on $Z$ ". We write "conv" for "convex hull of".

Lemma 2. We suppose that $f(X, Y)$ is bounded and $A \in R$. If $\phi \neq W \subset Y$ and $Z \subset Y$ we write $W \mathscr{R} Z$ if there exists $h \in l_{\infty}(X)$ such that, whenever $G \in \mathscr{F}(W \cup Z)$,

$$
S_{X}(\inf f(\cdot, G)-h)-\sup _{F \in \mathscr{T}(X)} \inf _{y \in W} S_{F}(f(\cdot, y)-h)>A .
$$

If $Y_{0} \mathscr{R} Z$ we write $t\left(Y_{0}, Z\right)=\inf _{\varnothing \neq W \subset Y_{0}, W: Z Z} \sup f(\cdot, W) \in l_{\infty}(X)$.

We suppose that $Y_{0} \mathscr{R} \phi$. Then we can choose $y_{1}, Y_{1}, y_{2}, Y_{2}, \cdots$ such that, for all $p \geqq 1$,

$$
y_{p} \in Y_{p-1} \text { and } Z_{p}=\left\{y_{1}, \cdots, y_{p}\right\} \text {, }
$$

$(4, \mathrm{p}) \quad \varnothing \neq Y_{p} \subset Y_{p-1}, Y_{p} \mathscr{R} Z_{p}, S_{X}\left(\inf f\left(\cdot, Z_{p}\right)-\sup f\left(\cdot, Y_{p}\right)\right)>A$,

and

$$
\left\{\begin{array}{l}
\text { for all } g \in \operatorname{conv} f\left(\cdot, Z_{p}\right) \\
\quad S_{X}\left(g-\sup f\left(\cdot, Y_{p}\right)\right)>S_{X}\left(g-t\left(Y_{p}, Z_{p}\right)\right)-\frac{1}{p}
\end{array}\right.
$$

Proof. We suppose inductively that $p \geqq 1$ and that, for all $n<p$, $y_{n}$ and $Y_{n}$ have been chosen so that $(3, n),(4, n)$, and $(5, n)$ are satisfied. We choose $y_{p} \in Y_{p-1}$ arbitrarily and define $Z_{p}$ so that $(3, p)$ is satisfied. Since $Y_{p-1} \mathscr{R} Z_{p-1}$ and $Y_{p-1} \cup Z_{p}=Y_{p-1} \cup Z_{p-1}$ (with the convention that $Z_{0}=\phi$ ), it follows that $Y_{p-1} \mathscr{R} Z_{p}$. Hence there exists $h \in l_{\infty}(X)$ such that (taking $G=Z_{p} \in \mathscr{F}\left(Y_{p-1} \cup Z_{p}\right)$ ) 


$$
S_{X}\left(\inf f\left(\cdot, Z_{p}\right)-h\right)-\alpha>A,
$$

where $\alpha=\sup _{F \in \mathscr{F}(X)} \inf _{y \in Y_{p-1}} S_{F}(f(\cdot, y)-h)$. Consequently there exist $x_{0} \in X$ and $\eta>0$ such that

$$
\inf f\left(x_{0}, Z_{p}\right)-h\left(x_{0}\right)-\alpha>A+\eta \text {. }
$$

We write $W_{0}=\left\{y: y \in Y_{p-1}, f\left(x_{0}, y\right)-h\left(x_{0}\right) \leqq \alpha+\eta\right\}$. If $F \in \mathscr{F}(X)$ then $F \cup\left\{x_{0}\right\} \in \mathscr{F}(X)$ hence

$$
\inf _{y \in Y_{p-1}}\left\{S_{F}(f(\cdot, y)-h) \vee\left(f\left(x_{0}, y\right)-h\left(x_{0}\right)\right)\right\} \leqq \alpha
$$

from which $\inf _{y \in W_{0}} S_{F}(f(\cdot, y)-h) \leqq \alpha$. We have proved that

$$
\sup _{F \in \mathscr{F}(X)} \inf _{y \in W_{0}} S_{F}(f(\cdot, y)-h) \leqq \alpha
$$

and it follows easily from this and $Y_{p-1} \mathscr{R} Z_{p}$ that $W_{0} \mathscr{R} Z_{p}$. We next choose $g_{1}, \cdots, g_{s} \in \operatorname{conv} f\left(\cdot, Z_{p}\right)$ so that, for all $g \in \operatorname{conv} f\left(\cdot, Z_{p}\right)$, there exists $r \in\{1, \cdots, s\}$ such that $S_{X}\left(\left|g-g_{r}\right|\right)<1 / 3 p$. We choose $W_{1}, \cdots, W_{s}$ in sequence as follows: we choose $W_{r}, \phi \neq W_{r} \subset W_{r-1}$ such that $W_{r} \mathscr{R} Z_{p}$ and

$$
S_{X}\left(g_{r}-\sup f\left(\cdot, W_{r}\right)\right)>S_{X}\left(g_{r}-t\left(W_{r-1}, Z_{p}\right)\right)-\frac{1}{3 p} .
$$

We write $Y_{p}=W_{s}$. It is immediate that $\phi \neq Y_{p} \subset Y_{p-1}$ and $Y_{p} \mathscr{R} Z_{p}$. Further

$$
\begin{aligned}
S_{X}\left(\inf f\left(\cdot, Z_{p}\right)-\sup f\left(\cdot, Y_{p}\right)\right) & \geqq S_{X}\left(\inf f\left(\cdot, Z_{p}\right)-\sup f\left(\cdot, W_{0}\right)\right) \\
& \geqq \inf f\left(x_{0}, Z_{p}\right)-\sup f\left(x_{0}, W_{0}\right) \\
& \geqq \inf f\left(x_{0}, Z_{p}\right)-h\left(x_{0}\right)-\alpha-\eta>A
\end{aligned}
$$

from the definition of $W_{0}$ and $(6)$. Hence $(4, \mathrm{p})$ is satisfied. Finally, if $g \in \operatorname{conv} f\left(\cdot, Z_{p}\right)$ we choose $r \in\{1, \cdots, s\}$ such that $S_{X}\left(\left|g-g_{r}\right|\right)<$ $1 / 3 p$. Then

$$
\begin{aligned}
S_{X}\left(g-\sup f\left(\cdot, Y_{p}\right)\right) & \geqq S_{X}\left(g-\sup f\left(\cdot, W_{r}\right)\right) \\
& >S_{X}\left(g_{r}-\sup f\left(\cdot, W_{r}\right)\right)-\frac{1}{3 p} \\
& >S_{X}\left(g_{r}-t\left(W_{r-1}, Z_{p}\right)\right)-\frac{2}{3 p} \\
& \geqq S_{X}\left(g-t\left(W_{r-1}, Z_{p}\right)\right)-\frac{1}{p} \\
& \geqq S_{X}\left(g-t\left(Y_{p}, Z_{p}\right)\right)-\frac{1}{p}
\end{aligned}
$$

Hence $(5, p)$ is satisfied and the Lemma is proved by induction. 
Lemma 3. We use the notation of Lemma 2 and suppose $p \geqq 1$.

(a) If $\left\{z_{n}\right\}_{n \geqq 1}$ is a subsequence of $\left\{y_{n}\right\}_{n>p}$ then $\left\{z_{n}: n \geqq 1\right\} \mathscr{R} Z_{p}$.

(b) We suppose that $g \in \operatorname{conv} f\left(\cdot, Z_{p}\right)$. Then

$$
S_{X}\left(g-\lim \sup _{n \rightarrow \infty} f\left(\cdot, y_{n}\right)\right) \geqq S_{X}\left(g-\lim \inf _{n \rightarrow \infty} f\left(\cdot, y_{n}\right)\right)-\frac{1}{p} .
$$

Proof. (a) We write $W=\left\{z_{n}: n \geqq 1\right\}$ and $h=\lim \sup _{n \rightarrow \infty} f\left(\cdot, z_{n}\right)$. If $F \in \mathscr{F}(X)$ then $\inf _{y \in W} S_{F}(f(\cdot, y)-h)=\inf _{n \geqq 1} S_{F}\left(f\left(\cdot, z_{n}\right)-h\right) \leqq$ $\lim \sup _{n \rightarrow \infty} S_{F}\left(f\left(\cdot, z_{n}\right)-h\right)=S_{F}\left(\lim \sup _{n \rightarrow \infty} f\left(\cdot, z_{n}\right)-h\right)=S_{F}(0)=0$. On the other hand if $G \in \mathscr{F}\left(W \cup Z_{p}\right)$ then there exists $q \geqq p$ such that $\inf f(\cdot, G) \geqq \inf f\left(\cdot, Z_{q}\right)$ and since $h \leqq \sup _{n>q} f\left(\cdot, y_{n}\right) \leqq \sup f\left(\cdot Y_{q}\right)$

$$
S_{X}(\inf f(\cdot, G)-h) \geqq S_{X}\left(\inf f\left(\cdot, Z_{q}\right)-\sup f\left(\cdot, Y_{q}\right)\right)>A
$$

from $(4, \mathrm{p})$. It follows that $W \mathscr{R} Z_{p}$, as required.

(b) If $\left\{z_{n}\right\}_{n \geqq 1}$ is as in (a) then, from (a) and $(5, \mathrm{p})$,

$$
\left\{\begin{aligned}
S_{Y}\left(g-\lim \sup _{n \rightarrow \infty} f\left(\cdot, y_{n}\right)\right) & \geqq S_{X}\left(g-\sup f\left(\cdot, Y_{p}\right)\right) \\
& \geqq S_{X}\left(g-\sup _{n \geqq 1} f\left(\cdot, z_{n}\right)\right)-\frac{1}{p} .
\end{aligned}\right.
$$

Now the liminf of a real sequence is the infimum of the suprema of all its subsequences (this is the crux of [6], Lemma 2) so, taking the supremum of the right-hand side of (7) over all subsequences $\left\{z_{n}\right\}_{n \geqq 1}$ of $\left\{y_{n}\right\}_{n>p}$ we get the required result.

Lemma 4. We use the notation of Lemma 2. If $g \in \operatorname{conv}\left\{f\left(\cdot, y_{n}\right)\right.$ : $n \geqq 1\}$ then

$$
S_{X}\left(g-\lim \sup _{n \rightarrow \infty} f\left(\cdot, y_{n}\right)\right)=S_{X}\left(g-\lim \inf _{n \rightarrow \infty} f\left(\cdot, y_{n}\right)\right)>A .
$$

Proof. If $p$ is sufficiently large then $g \in \operatorname{conv} f\left(\cdot, Z_{p}\right)$. The equality follows from Lemma $3(\mathrm{~b})$ by letting $p \rightarrow \infty$ and the inequality follows from $(4, \mathrm{p})$.

Theorem 5. We suppose that $f(X, Y)$ is bounded and, whenever $0<\lambda<1$ and $\left\{k_{n}: n \geqq 1\right\} \subset \operatorname{conv} f(\cdot, Y)$ then there exists $k \in l_{\infty}(X)$ such that $\lim \inf _{n \rightarrow \infty} k_{n} \leqq k \leqq \lim \sup _{n \rightarrow \infty} k_{n}$ and $\sum_{n \geqq 1} \lambda^{n-1}\left(k_{n}-k\right)$ attains its supremum on $X$. Then (1) holds.

Proof. If (1) does not hold then, for an appropriate $A>0$ (taking $h=0) Y \mathscr{R} \phi$. From Lemmas 2 and 4 , there exists $\left\{y_{n}: n \geqq 1\right\} \subset Y$ such that, whenever $g \in \operatorname{conv}\{f(\cdot, y): n \geqq 1\}$, (8) holds. For $m \geqq 1$ we write $f_{m}=f\left(\cdot, y_{m}\right)-\lim \sup _{n \rightarrow \infty} f\left(\cdot, y_{n}\right)$ and $B=\sup _{n \geqq 1} S_{X}\left(f_{n}\right)$. We 
write $\delta=A / 3>0$ and choose $\lambda>0, g_{1}, g_{2}, \cdots$ as in [9], Lemma 2. Proceeding as therein we obtain ([9], relation (3)) for all $m \geqq 1$

$$
S_{X}\left(\sum_{n \leqq m} \lambda^{n-1} g_{n}\right)-S_{X}\left(\sum_{n \leq m-1} \lambda^{n-1} g_{n}\right) \geqq[A-\delta(1+\lambda)] \lambda^{m-1} \cdot
$$

For all $m \geqq 1$ there exists $k_{m} \in \operatorname{conv}\left\{f\left(\cdot, y_{n}\right): n \geqq m\right\}$ such that $g_{m}=$ $k_{m}-\lim \sup _{n \rightarrow \infty} f\left(\cdot, y_{n}\right)$. We choose $k \in l_{\infty}(X)$ as in the statement of the theorem and write $g_{m}^{\prime}=k_{m}-k$. Since $\lim _{\inf _{n \rightarrow \infty}} f\left(\cdot, y_{n}\right) \leqq k \leqq$ lim $\sup _{n \rightarrow \infty} f\left(\cdot, y_{n}\right)$, it follows from (8) that, for all $m \geqq 1$,

$$
S_{X}\left(\sum_{n \leqq m} \lambda^{n-1} g_{n}^{\prime}\right)=S_{X}\left(\sum_{n \leqq m} \lambda^{n-1} g_{n}\right) \text {. }
$$

Thus (9) is true with $g_{n}$ replaced by $g_{n}^{\prime}$. Since $\sum_{n \leqq 1} \lambda^{n-1} g_{n}^{\prime}$ attains its supremum on $X$ we can continue as in [9], Lemma 2 and find $x \in X$ such that, for all $m \geqq 1, g_{m}^{\prime}(x) \geqq A-2 \delta=A / 3$, i.e., $k_{m}(x) \geqq k(x)+A / 3$. This contradicts our assumption that $k \geqq \lim \inf _{n \rightarrow \infty} k_{n}$.

2. Topological conditions implying the maximinimax relation.

REMARK 6. If $X$ is a compact topological space and, for all $y \in$ $Y, f(\cdot, y)$ is uppersemicontinuous on $X$ then (1) holds.

Proof. If $\alpha<\inf _{G \in \mathscr{F}(Y)} \sup _{x \in X} \inf f(x, G)$ then, for all $G \in \mathscr{F}(Y)$, $\bigcap_{y \in G}\{x: x \in X, f(x, y) \geqq \alpha\} \neq \phi$. From compactness, $\bigcap_{y \in Y}\{x: x \in X$, $f(x, y) \geqq \alpha\} \neq \phi$ hence $\sup _{x \in X} \inf f(x, Y) \geqq \alpha$. It follows that

$$
\inf _{G \in \mathscr{F}(Y)} \sup _{x \in X} \inf f(x, G) \leqq \sup _{x \in X} \inf f(x, Y)
$$

and so (1) certainly holds.

REMARK 7. If $X$ and $Y$ are countably compact topological spaces and $f$ is separately continuous then (1) holds.

Proof. If

$$
\alpha<\inf _{G \in \mathscr{T}(Y)} \sup _{x \in X} \inf f(x, G) \text { and } \sup _{F \in \mathscr{T}(X)} \inf _{y \in Y} \sup f(F, y)<\beta
$$

then we can construct inductively $\left\{x_{n}: n \geqq 1\right\} \subset X$ and $\left\{y_{n}: n \geqq 1\right\} \subset Y$ such that $f\left(x_{m}, y_{n}\right) \leqq \beta$ when $1 \leqq m \leqq n$ and $f\left(x_{m}, y_{n}\right) \geqq \alpha$ when $1 \leqq$ $n<m$. We suppose that $x_{0} \in X$ is a cluster point of $\left\{x_{n}\right\}_{n \geqq 1}$ and $y_{0} \in$ $Y$ is a cluster point of $\left\{y_{n}\right\}_{n \geqq 1}$. Then simultaneously $f\left(x_{0}, y_{0}\right) \leqq \beta$ and $f\left(x_{0}, y_{0}\right) \geqq \alpha$, hence $\alpha \leqq \beta$. Thus (1) holds.

REMARK 8. If $X$ is a pseudocompact topological space, $f(X, Y)$ is bounded and each sequence from $\operatorname{conv} f(\cdot, Y)$ has a continuous cluster 
point in the topology of pointwise convergence on $X$ then (1) is true.

Proof. This is immediate from Theorem 5.

3. Some old and new minimax theorems for concave-convex functions.

Lemma 9. We suppose that $X$ is a nonempty convex subset of a real linear space and $a_{1}, \cdots, a_{m}$ are real concave functions on $X$. Then there exist $\lambda_{1}, \cdots, \lambda_{m} \geqq 0, \lambda_{1}+\cdots+\lambda_{m}=1$ such that

$$
S_{X}\left(\lambda_{1} a_{1}+\cdots+\lambda_{m} a_{m}\right)=S_{X}\left(a_{1} \wedge \cdots \wedge a_{m}\right) \text {. }
$$

Proof. The result is immediate if $S_{X}\left(a_{1} \wedge \cdots \wedge a_{m}\right)=\infty$ so we suppose that $S_{X}\left(a_{1} \wedge \cdots \wedge a_{m}\right)<\infty$. If $f \in R^{m}$ we write

$$
\alpha(f)=S_{X}\left[\left(a_{1}-f(1)\right) \wedge \cdots \wedge\left(a_{m}-f(m)\right)\right]
$$

$\alpha$ is a well-defined concave function on $R^{m}$. If $f \in R^{m}$ we write

$$
\beta(f)=\inf _{\lambda>0} \lambda\left[\alpha(0)-\alpha\left(\frac{f}{\lambda}\right)\right] \text {. }
$$

Then $\beta$ is a well-defined sublinear functional on $R^{m}$. From the HahnBanach theorem there exist $\lambda_{1}, \cdots, \lambda_{m}$ such that

$$
\text { for all } f \in R^{m} \lambda_{1} f(1)+\cdots+\lambda_{m} f(m) \leqq \beta(f) \text {. }
$$

For all $f \in R^{m}, \beta(f) \leqq f(1) \vee \cdots \vee f(m)$, hence $\lambda_{1}, \cdots, \lambda_{m} \geqq 0$ and $\lambda_{1}+\cdots+\lambda_{m}=1$. Further

$$
\begin{aligned}
S_{X}\left(\lambda_{1} a_{1}+\cdots+\lambda_{m} a_{m}\right) \\
\quad \leqq \sup _{y \in X} \beta\left(a_{1}(y), \cdots, a_{m}(y)\right) \\
\quad \leqq \sup _{y \in X}\left[\alpha(0)-\alpha\left(a_{1}(y), \cdots, a_{m}(y)\right)\right] \\
\quad=\alpha(0)-\inf _{y \in X} \sup _{x \in X}\left[\left(a_{1}(x)-a_{1}(y)\right) \wedge \cdots \wedge\left(a_{m}(x)-a_{m}(y)\right)\right] \\
\quad \leqq \alpha(0)=S_{X}\left(a_{1} \wedge \cdots \wedge a_{m}\right) .
\end{aligned}
$$

REMARK 10. The axiom of choice is not used in Lemma 9. (The Hahn-Banach theorem is used only in $R^{m}$.) Using the axiom of choice one can prove the following extension: if $N \neq \varnothing$, for all $n \in N, a_{n}$ is a real concave function on $X$ and, for all $x \in X, a .(x) \in l_{\infty}(N)$ then there exists a positive linear functional $\mu$ on $l_{\infty}(N)$ such that $\mu(1)=1$ and $\sup _{x \in X} \mu(a .(x))=S_{X}\left(\inf _{n \in N} a_{n}\right)$. This is closely related to the following result: if $S$ is a sublinear functional on a real linear space $E$ and $D$ is a nonempty convex subset of $E$ then there exists a linear func- 
tional $\varphi$ on $E$ such that $\varphi$ is dominated by $S$ on $E$ and $\inf \varphi(D)=$ inf $S(D)$. This latter result is discussed in [4], [5], and [8], Theorem 28(d) and Remark 29.

We point out that Lemma 9 can be deduced from known minimax theorems. On the other hand Lemma 9 generalizes [2], Theorem 6 .

LEMmA 11. We suppose that $X$ and $Y$ are nonempty convex subsets of real linear spaces and

$$
\begin{gathered}
\text { for all } y \in Y \quad f(\cdot, y) \text { is concave on } X, \\
\text { for all } x \in X \quad f(x, \cdot) \text { is convex on } Y,
\end{gathered}
$$

then

$$
\inf _{G \in X(Y)} \sup _{x \in X} \inf f(x, G)=\inf _{y \in Y} \sup f(X, y)
$$

and

$$
\sup _{F \in \mathscr{J}(X)} \inf _{y \in Y} \sup f(F, y)=\sup _{x \in X} \inf f(x, Y)
$$

Proof. If $G=\left\{y_{1}, \cdots, y_{m}\right\} \in \mathscr{F}(Y)$ then, from (10) and Lemma 9, there exist $\lambda_{1}, \cdots, \lambda_{m} \geqq 0, \lambda_{1}+\cdots+\lambda_{m}=1$ such that

$$
S_{X}\left(\lambda_{1} f\left(\cdot, y_{1}\right)+\cdots+\lambda_{m} f\left(\cdot, y_{m}\right)\right)=\sup _{x \in X} \inf f(x, G) \cdot
$$

From (11), if

$$
y=\lambda_{1} y_{1}+\cdots+\lambda_{m} y_{m} \in Y \text { then } \sup f(X, y) \leqq \sup _{x \in X} \inf f(x, G) .
$$

This establishes “ $\geqq$ " in (12) and "ฏ” is trivial. (13) is proved by an analogous argument. (Compare [1], Theorem 1.)

THEOREM 12. We suppose that $X, Y$ and $f$ satisfy the conditions of Lemma 11 and Theorem 5. Then (2) holds.

Proof. This is immediate from Theorem 5 and Lemma 11.

REMARK 13. Arguing as above, we can prove easily that if $X, Y$ and $f$ satisfy the conditions of Lemma 11 and either Remark 6, 7, or 8 then (2) is satisfied. The first of these results is well known; the other two do not seem to be.

THEOREM 14. We suppose that $E$ is a real Hausdorff locally convex space with dual $E^{\prime}$ and that $X$ is a nonempty bounded convex subset of $E$. Then $(14) \Rightarrow(15) \Rightarrow(16) \Rightarrow(17) \Leftrightarrow(18)$. 


$$
X \text { is } w\left(E, E^{\prime}\right) \text {-compact }
$$

There exists $Z$ such that $X=\operatorname{conv}^{-} Z$ and $Z$ is $w\left(E, E^{\prime}\right)$-compact

$$
\text { For all } \varphi \in E^{\prime}, \varnothing \text { attains its supremum on } X
$$

Whenever $Y$ is a nonempty convex equicontinuous subset $\left\{\right.$ of $E^{\prime}$ then $\inf _{y \in Y} \sup \langle X, y\rangle \leqq \sup _{x \in Y} \inf \langle x, Y\rangle$

$$
\left\{\begin{array}{l}
\text { Whenever } Y \text { is a nonempty convex equicontinuous subset } \\
\text { of } E^{\prime} \text { and } d \in Z \text { then } \inf _{x \in X} S_{Y}(d-\langle x, \cdot\rangle) \leqq 0 \text {, where } Z \text { stands } \\
\text { for the closure in } R^{E^{\prime}} \text { of }\{\langle x, \cdot\rangle: x \in X\} .
\end{array}\right.
$$

Proof. It is trivial that $(14) \Rightarrow(15)$ and immediate from the bipolar theorem that $(15) \Longrightarrow(16)$. It follows from Theorem 12 that $(16) \Rightarrow(17)$. (If $\left\{y_{n}: n \geqq 1\right\} \subset Y$ and $y \in E^{\prime}$ is a $w\left(E^{\prime}, E\right)$-cluster point of $\left\{y_{n}\right\}_{n \geqq 1}$ then, for all $x \in X$, liminf $\operatorname{in}_{n \rightarrow \infty}\left\langle x, y_{n}\right\rangle \leqq\langle x, y\rangle \leqq \lim \sup _{n \rightarrow \infty}\left\langle x, y_{n}\right\rangle$. Consequently the conditions of Theorem 5 are satisfied.)

$(17) \Rightarrow(18)$. We suppose that $Y, Z$ and $d$ are as in (18) and $\delta>0$. Since $d$ is bounded and affine on $Y$ we can write $Y=Y_{1} \cup \cdots \cup Y_{m}$ where, for all $n=1, \cdots, m, Y_{n}$ is nonempty and convex and $\sup d\left(Y_{n}\right)-$ $\inf d\left(Y_{n}\right) \leqq \delta$. From (17) (with $Y$ replaced by $Y_{n}$ ) there exists $x_{n} \in X$ such that

$$
\begin{aligned}
\inf \left\langle x_{n}, Y_{n}\right\rangle & \geqq \inf \sup \langle X, y\rangle-\delta \\
& \geqq \inf d\left(Y_{n}\right)-\delta \quad \text { since } d \in Z \\
& \geqq \sup d\left(Y_{n}\right)-2 \delta \quad \text { from the choice of } Y_{n} .
\end{aligned}
$$

From Lemma 9, there exists $x \in X$ such that

$$
\begin{aligned}
S_{Y}(d-\langle x, \cdot\rangle) & =S_{Y}\left(\left(d-\left\langle x_{1}, \cdot\right\rangle\right) \wedge \cdots \wedge\left(d-\left\langle x_{m}, \cdot\right\rangle\right)\right) \\
& \leqq \sup _{1 \leqq n \leqq m} S_{Y_{n}}\left(d-\left\langle x_{n}, \cdot\right\rangle\right) \\
& \leqq \sup _{1 \leqq n \leqq m}\left[\sup d\left(Y_{n}\right)-\inf \left\langle x_{n}, Y_{n}\right\rangle\right] \leqq 2 \delta
\end{aligned}
$$

from the inequalities above. The result follows since $\delta>0$ is arbitrary.

$(18) \Rightarrow(17)$. We suppose that $Y$ is as in (17) and we define $Z$ as in (18). We suppose, further, that $\alpha<\inf _{y \in Y} \sup \langle X, y\rangle$. If $G \in \mathscr{F}(Y)$ then, from Lemma 9, there exists $y \in Y$ such that $\sup \langle X, y\rangle=$ $\sup _{x \in X} \inf \langle x, G\rangle$, hence $\sup _{x \in X} \inf \langle x, G\rangle>\alpha$. Consequently

$$
\bigcap_{y \in G}\{d: d \in Z, d(y) \geqq \alpha\} \supset \bigcap_{y \in G}\{\langle x, \cdot\rangle: x \in X,\langle x, y\rangle \geqq \alpha\} \neq \varnothing .
$$

From Tychonoff's theorem, $Z$ is compact hence $\bigcap_{y \in Y}\{d: d \in Z, d(y) \geqq$ $\alpha\} \neq \varnothing$ from which there exists $d \in Z$ such that inf $d(Y) \geqq \alpha$. (Compare the proof of Remark 6.) From (18) 


$$
\begin{aligned}
0 & \geqq \inf _{x \in X} S_{Y}(d-\langle x, \cdot\rangle) \geqq \inf _{x \in X}(\inf d(Y)-\inf \langle x, Y\rangle) \\
& =\inf d(Y)-\sup _{x \in X} \inf \langle x, Y\rangle \geqq \alpha-\sup _{x \in X} \inf \langle x, Y\rangle
\end{aligned}
$$

i.e.,

$$
\alpha \leqq \sup _{x \in X} \inf \langle x, Y\rangle
$$

The result follows since $\alpha<\inf _{y \in Y} \sup \langle X, y\rangle$ is arbitrary.

4. A converse minimax theorem, James's Theorem and Krein's theorem.

Theorem 15. We suppose that $E, E^{\prime}$ and $X$ are as in Theorem 14 and that $X$ is complete. If (17) is true then $X$ is $w\left(E, E^{\prime}\right)$-compact.

Proof. We suppose that $Z, d$ are as in (18) and we write $\mathscr{C}$ for the family of closed, circled neighborhoods of 0 in $E$ directed by $\subset$. If $U \in \mathscr{Q}$ then, since $(17) \Rightarrow(18)$, there exists $\psi(U) \in X$ such that $S_{U^{0}}(|d-\langle\psi(U), \cdot\rangle|) \leqq 1 / 2$. (The absolute value can be put in because $d-\langle\psi(U), \cdot\rangle$ is linear on $E^{\prime}$ and $U^{0}$ is symmetric.) If $U, V, W \in \mathscr{U}$ and $V, W \subset U$ then $\psi(V)-\psi(W) \in U^{00}=U$ hence the net $\psi$ is Cauchy in $X$. Since $X$ is complete, there exists $x \in X$ such that $\psi \rightarrow x$. We suppose that $y \in E^{\prime}$. If $U \in \mathscr{Q}$ and $U^{0} \ni y$ then $|d(y)-\langle\psi(U), y\rangle| \leqq$ $1 / 2$ and, passing to the limit, $|d(y)-\langle x, y\rangle| \leqq 1 / 2$. By homogeneity, $d=\langle x, \cdot\rangle \in R^{E^{\prime}}$. We have proved that $\langle X, \cdot\rangle$ is closed in $R^{E^{\prime}}$ hence, by Tychonoff's theorem, $X$ is $w\left(E, E^{\prime}\right)$-compact.

Theorem 16. We suppose that $E, E^{\prime}$ and $X$ are as in Theorem 15. Then (14), (15) and (16) are equivalent.

Proof. This is immediate from Theorems 14 and 15. (14) $\Leftrightarrow(15)$ is Krein's Theorem and (14) $\Leftrightarrow(16)$ is James's Theorem. (See [3], [6], and [7].)

\section{REFERENCES}

1. K. Fan, Minimax theorems, Proc. Nat. Acad. Sci., 39 (1953), 42-47.

2. Applications of a theorem concerning sets with convex sections, Math. Annalen, 163 (1966), 189-203.

3. R. C. James, Weakly compact sets. Trans. Amer. Math. Soc., 13 (1964), 129-140.

4. H. Konig, Über das von Neumannsche Minimax-Theorem, Arch. Math., 19 (1968), 482-487.

5. On certain applications of the Hahn-Banach and Minimax theorems, Arch. Math., 21 (1970), 583-591. 
6. J. D. Pryce, Weak compactness in locally convex spaces, Proc. Amer. Math. Soc., 17 (1966). 148-155.

7. D. Sibony, Le Théorème de James, Sem. Brelot. Choquet et Deny (Théorie du Potential), 12 (1967/68), nº, 5p (1969).

8. S. Simons, Minimal sublinear functionals, Studia Math., 37 (1970), 37-56.

9. — A convergence theorem with boundary, To precede this paper.

Received January 28, 1971. This research was supported in part by NSF Grant number 20632. Some of this paper was presented at the International Colloquium on Functional analysis in Liège, Belgium during September, 1970. I would like to express my thanks to Professor Ky Fan for a number of helpful discussions about minimax theorems.

University of CALifornia, SANTA Barbara 


\section{PACIFIC JOURNAL OF MATHEMATICS}

\section{EDITORS}

\section{H. SAMELSON}

Stanford University

Stanford, California 94305

\section{R. HOBBY}

University of Washington Seattle, Washington 98105

\section{J. DugundJI}

Department of Mathematics University of Southern California Los Angeles, California 90007

RICHARD ARENS

University of California Los Angeles, California 90024

\section{ASSOCIATE EDITORS}
E. F. BECKENBACH
B. H. Neumann
F. WoLF
K. YoSHIDA

\section{SUPPORTING INSTITUTIONS}

UNIVERSITY OF BRITISH COLUMBIA CALIFORNIA INSTITUTE OF TECHNOLOGY

UNIVERSITY OF CALIFORNIA

MONTANA STATE UNIVERSITY

UNIVERSITY OF NEVADA

NEW MEXICO STATE UNIVERSITY

OREGON STATE UNIVERSITY

UNIVERSITY OF OREGON

OSAKA UNIVERSITY

\author{
UNIVERSITY OF SOUTHERN CALIFORNIA \\ STANFORD UNIVERSITY \\ UNIVERSITY OF TOKYO \\ UNIVERSITY OF UTAH \\ WASHINGTON STATE UNIVERSITY \\ UNIVERSITY OF WASHINGTON \\ * * * * \\ AMERICAN MATHEMATICAL SOCIETY \\ NAVAL WEAPONS CENTER
}

The Supporting Institutions listed above contribute to the cost of publication of this Journal, but they are not owners or publishers and have no responsibility for its content or policies.

Mathematical papers intended for publication in the Pacific Journal of Mathematics should be in typed form or offset-reproduced, (not dittoed), double spaced with large margins. Underline Greek letters in red, German in green, and script in blue. The first paragraph or two must be capable of being used separately as a synopsis of the entire paper. The editorial "we" must not be used in the synopsis, and items of the bibliography should not be cited there unless absolutely necessary, in which case they must be identified by author and Journal, rather than by item number. Manuscripts, in duplicate if possible, may be sent to any one of the four editors. Please classify according to the scheme of Math. Rev. Index. to Vol. 39. All other communications to the editors should be addressed to the managing editor, Richard Arens, University of California, Los Angeles, California, 90024.

50 reprints are provided free for each article; additional copies may be obtained at cost in multiples of 50 .

The Pacific Journal of Mathematics is published monthly. Effective with Volume 16 the price per volume (3 numbers) is $\$ 8.00$; single issues, $\$ 3.00$. Special price for current issues to individual faculty members of supporting institutions and to individual members of the American Mathematical Society: $\$ 4.00$ per volume; single issues $\$ 1.50$. Back numbers are available.

Subscriptions, orders for back numbers, and changes of address should be sent to Pacific Journal of Mathematics, 103 Highland Boulevard, Berkeley, California, 94708.

PUBLISHED BY PACIFIC JOURNAL OF MATHEMATICS, A NON-PROFIT CORPORATION

Printed at Kokusai Bunken Insatsusha (International Academic Printing Co., Ltd.), 270, 3-chome Totsuka-cho, Shinjuku-ku, Tokyo 160, Japan. 


\section{Pacific Journal of Mathematics}

\section{Vol. 40, No. $3 \quad$ November, 1972}

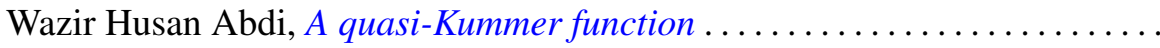

Vasily Cateforis, Minimal injective cogenerators for the class of modules of

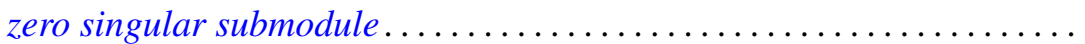

W. Wistar (William) Comfort and Anthony Wood Hager, Cardinality of

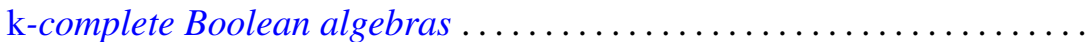

Richard Brian Darst and Gene Allen DeBoth, Norm convergence of martingales of Radon-Nikodym derivatives given a $\sigma$-lattice ..........

M. Edelstein and Anthony Charles Thompson, Some results on nearest points and support properties of convex sets in $c_{0} \ldots \ldots \ldots \ldots \ldots$

Richard Goodrick, Two bridge knots are alternating knots .

Jean-Pierre Gossez and Enrique José Lami Dozo, Some geometric properties related to the fixed point theory for nonexpansive mappings ..........

Dang Xuan Hong, Covering relations among lattice varieties .............

Carl Groos Jockusch, Jr. and Robert Irving Soare, Degrees of members of $\Pi_{1}^{0}$

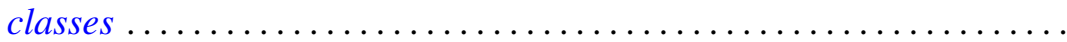

565

575

605

Leroy Milton Kelly and R. Rottenberg, Simple points in pseudoline

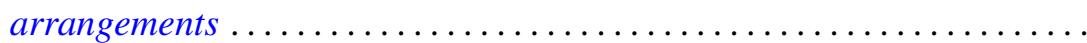

Joe Eckley Kirk, Jr., The uniformizing function for a class of Riemann surfaces....

Glenn Richard Luecke, Operators satisfying condition $\left(G_{1}\right)$ locally ... 629

T. S. Motzkin, On L $(S)$-tuples and l-pairs of matrices ... . .

Charles Estep Murley, The classification of certain classes of torsion free

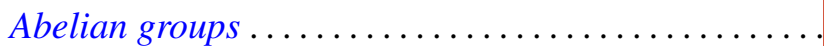

Louis D. Nel, Lattices of lower semi-continuous functions and associated topological spaces.

David Emroy Penney, II, Establishing isomorphism between tame prime

knots in $E^{3}$. . .

Daniel Rider, Functions which operate on $\mathscr{F} L_{p}(T), 1<p<2$

Thomas Stephen Shores, Injective modules over duo rings ...

Stephen Simons, A convergence theorem with boundary. .

703

Stephen Simons, Maximinimax, minimax, and antiminimax theorems and a

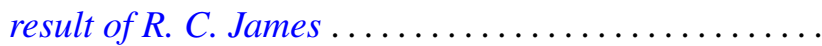

Stephen Simons, On Ptak's combinatorial lemma ........

Stuart A. Steinberg, Finitely-valued $f$-modules............

Pui-kei Wong, Integral inequalities of Wirtinger-type and fourth-order

elliptic differential inequalities .

Yen-Yi Wu, Completions of Boolean algebras with partially additive

operators ..................................

Phillip Lee Zenor, On spaces with regular $G_{\delta}$-diagonals . . . 